\title{
Characterization of yeast in hapludands soil with biotechnological potential
}

\author{
Paola E. Díaz ${ }^{1 *}$, Camila Aranda ${ }^{1}$, Oscar Martínez ${ }^{1}$, Roberto Godoy ${ }^{2}$, Aldo Gonzales ${ }^{3}$ \\ Eduardo Valenzuela ${ }^{1}$
}

${ }^{1}$ Institute of Biochemistry and Microbiology, Faculty of Sciences, University Austral of Chile. Casilla 167, Valdivia 5090000, Chile, Phone: 0056 632221296. ${ }^{2}$ Institute of Environmental and Evolutionary Sciences, Faculty of Science University Austral of Chile. Casilla 567, Valdivia 5090000, Chile. ${ }^{3}$ Severo Ochoa Centre for Molecular Biology (CBMSO), University Autónoma of Madrid, C/Nicolás Cabrera, 1. 28049 Madrid, España. *Corresponding author: paola.diaz@postgrado.uach.cl

\begin{abstract}
Yeasts play an important role in nature, and soil is one of the largest reservoirs of yeasts. Seventy-seven yeast strains were isolated from southern Chilean volcanic ash soil. These 77 strains were composed of 30 strains derived from soils used as permanent grassland, 30 strains from rotating grassland, and 17 strains from native forest (considered as the control). These strains were identified using restriction fragment length polymorphisms (PCR-RFLP) in conjunction with ITS-5.8S rDNA sequencing. Additionally, a physiological characterization of the assimilation of carbon and nitrogen and the fermentation of sugars was performed. Various features of the strains were evaluated including their growth in vinasse medium, nitrogen and phosphorus content, and lipid production. Lastly, the use of strains as biofertilizers was analyzed via the cultivation of bell pepper seedlings in soil. From the RFLP profiles, the 77 strains clustered into 10 groups. Of these, only three groups could be identified to the species level, and another was classified to the level of genus (Devaryomyces hansenii, Pichia fermentan, Kazachstania exigua, Candida sp.). All strains grew in vinasse medium. Six strains (PP1, PP4, PR4, PR10, PR27 and PR29) showed a high capacity to accumulate lipids, and three strains (PP1, PP21 and PR28) have the potential to be used as biofertilizers.
\end{abstract}

Keywords: Yeast, PCR-RFLP, ITS-5.8S, lipids, biofertilizers 


\section{Introduction}

The conditions found in soil facilitate the development of certain species of yeast; thus, a high diversity of yeast contributes to the soil microbial community (Wuczkowski and Prillinger, 2004). The diversity of yeasts in soil has been examined globally from Antarctica to tropical regions (Slavikova and Vadkertiova, 2000), and soil type, climatic features, and anthropic disturbance have been found to influence the presence of yeasts in soil. Recently, several studies have demonstrated how human activity influences the diversity and community structure of yeasts in soil. Slavikova and Vadkertiova (2003) compared yeasts in soils where different crops (maize, beet and potatoes) were grown versus non-tilled soils and determined that there is a decrease in yeast population in cultivated soils likely due to the use of pesticides and fungicides. Yurkov et al. (2012) analyzed yeast diversity in soils whose use had changed from forest to pasture, and they found that pasture soils preferentially harbor Ascomycete yeasts as opposed to forest soils where the community structure is more heterogeneous.

The economic potential of yeast to agriculture, medical, or environmental applications warrants their molecular identification. Currently, molecular barcoding employing rDNA genes or the internal transcribed spacer (ITS) is the most common technique used to characterize yeast (Pham et al., 2011). Molecular barcoding is fast, reliable, accurate and therefore, suitable for rapid screening of isolated strains. It has been shown that ITS regions (non-coding and variable) and the 5.8 rRNA gene (coding and conserved) may be useful for the measurement of phylogenetic relationships since these regions present high intraspecific differences (Fernández-González et al., 2001). Currently, there are various applications for the use of yeast in industry including in the production of biofertilizers and lipids. Biofertilizers are composites of beneficial microorganisms, which, after application, can increase nutrient availability and thus help improve soil health (Kupper et al., 2006). Given that many agricultural systems are characterized by low efficiency in the use of nutrients, agricultural practices that minimize the excessive addition of $\mathrm{N}$ and $\mathrm{P}$ are urgently needed in order to ensure sustainable food cultivation Yurkov et al. (2012). El-Tarabily and Sivasithamparam (2006) note that yeast taxa have been registered as plant endophytes, as promoters of plant growth, as producers of enzymes (e.g., $\beta-1,3-$ glucanasa), and as agents of biological control. Additionally, Ignatova et al. (2015) have shown that yeast directly or indirectly provide beneficial services to plants. Some of these services include nitrogen fixation, the production of plant hormones such as auxins, gibberellins, and cytokines, the synthesis of vitamins, the production of antifungal and antibiotic compounds, the ability to solubilize minerals such as phosphorous, and the capacity to degrade numerous chemically toxic substances.

Additionally, yeasts have been reported (Chang et al., 2013) as the most promising species for the production of lipids. Specifically, the high intercellular lipid accumulation (up to $80 \%$ of cell dry weight) of some species, namely Rhodosporidium sp., Rhodotorula sp., Lipomyces sp., and Yarrowia lipolytica, make them very useful for the production of fats (Rakicka et al., 2015). Many of these yeasts accumulate lipids in the form of trialkylglycerols (TAGs), mainly in the cytoplasmic membrane, and the production of TAGs increases during nutrient limitation (Arous et al., 2015). Currently, research on the accumulation of yeast lipids and lipids generated by other oil-producing microorganisms is mainly focused on: (i) optimizing pilot-scale lipid production including residual raw materials as a source of energy (Polburee et al., 2015), 
(ii) the search for strategies in the culture to optimize the lipid production process and (iii) the determination of metabolic and molecular aspects involved in lipid accumulation (Ledesma-Amaro et al., 2016). The objective of the present study was to identify and characterize yeasts that are present in volcanic ash soils in the Los Rios Region of Chile. Furthermore, we evaluated the biotechnological potential of these yeasts by growing them in an industrial waste liquid known as vinasse.

\section{Materials and Methods}

\subsection{Collecting soil samples}

Samples were collected from various sites with volcanic ash soil (Hapludands) in the town of Marquina, Valdivia, Chile $\left(673.75^{\circ} \mathrm{E}, 5625.5^{\circ} \mathrm{N}\right.$ UTM, Quadrant H18). Specifically, $400 \mathrm{~g}$ samples were collected from the first $10 \mathrm{~cm}$ of the soil. The sample sites included permanent grassland (PP), rotating grassland (PR), and native forest (B) that was considered as the control. Two samples were randomly collect from each site. The soil samples were deposited independently in sterile plastic bags and transferred to the Mycology Laboratory of the Institute of Biochemistry and Microbiology of the Austral University of Chile.

\subsection{Isolation of yeasts}

Isolation of yeasts was done by serial dilution whereby $10 \mathrm{~g}$ of the respective soil samples were weighed and placed in a flask. Then, $90 \mathrm{~mL}$ of sterile distilled water was added, and the obtained mixture was shaken manually until total dissolution of the soil was achieved. Following this, $1 \mathrm{~mL}$ of the mixture was extracted using a sterile pipette and placed in a tube containing $9 \mathrm{~mL}$ of sterile distilled water (10-2 dilution). Hence, dilutions were made up to 10-6. Subsequently,
$1 \mathrm{~mL}$ of the respective dilution was deposited in an empty Petri dish to which $0.5 \mathrm{~mL}$ of antibiotic mixture (penicillin and streptomycin 1:1) and $15 \mathrm{~mL}$ of Sabouraud agar were added. Once the agar had solidified, the plates were incubated at $23 \pm 2{ }^{\circ} \mathrm{C}$ for seven days. After the incubation, 30 yeast colonies were selected for each grassland site, and 17 colonies were selected for the control site. Colonies were selected using morphological criteria, including the color and the size of the colony. Overall, 77 yeast strains were selected for downstream analysis.

\subsection{Metabolic determination of yeast strains}

Each strain was characterized using the traditional methodology proposed by Barnett et al. (2000). Using an auxanogram, we determined how the yeasts used different carbon sources (succinic acid, citric acid, starch, cellobiose, Arabinose, D-glucitol, D-mannitol, D-xylose, D-ribose, DL-lactic acid, Galactitol, Galactose, Glycerol, Inositol, Lactose, L-aravinose, L-Rhamnose, L-sorbose, Maltose, Melibiosa, Melizotosa, Rafinosa, Ribitol, Sucrose, Trehalose). Specifically, $0.5 \mathrm{~mL}$ of yeast suspension (McFarland 0.1 turbidity $=10^{2} \mathrm{CFU}$ yeast $/ \mathrm{mL}$ ) was mixed with 10 $\mathrm{mL}$ of Yeast Nitrogen Base (YNB) agar, and the obtained mixture was deposited in a sterile and empty Petri dish. Once solidified, the selected carbon sources were deposited at four points that were equidistant from the plate edge. Glucose was used as a control. Following additions, the plates were incubated at 23 ${ }^{\circ} \mathrm{C}$ and examined every two days for one week. The qualitative growth of the yeast strain was given as positive (+), weakly positive (+/-), or negative (-). Nitrate, nitrite, and urea nitrogen assimilation was also tested by changing the base medium to Yeast Carbon Base (YCB) agar. Additionally, fermentation was evaluated. Specifically, glucose was used as a positive control, and the following were added at a $2 \%$ final 
concentration: Starch, D- Galactose, D-xylose, Fructose, Lactose, Maltose, Sucrose, Trehalose. As with the broth culture medium, $0.1 \%$ of yeast extract broth was used. To this, the sugar to be evaluated was added at a $2 \%$ final concentration. Overall, $3 \mathrm{~mL}$ of culture medium and $1.5 \mathrm{~mL}$ of the sugar to be tested were added to individual tubes. Then, $0.1 \mathrm{~mL}$ of the respective yeast suspension (at McFarland 0.1 ) was added to each tube, and then these were incubated at $23{ }^{\circ} \mathrm{C}$ for one month. Each day, visual checks for turbidity and gas in the Durham tubes were performed to determine whether fermentation was occurring.

\subsection{DNA extraction and amplification of the ITS rDNA region}

The same yeast isolates used in the metabolic analyses were also cultured in Yeast Peptone Dextrose (YPD) for $30 \mathrm{~h}$ at $25{ }^{\circ} \mathrm{C}$. Following this, the DNA of the strains was extracted using an E.Z.N.A. ${ }^{\circledR}$ Yeast DNA Kit following the supplier's instructions. The 5.8SITS region of the nuclear ribosomal DNA ( $\mathrm{rDNA}$ ) was amplified using the ITS1 primer (5' TCCGTAGGTGAACCTGCG G-3') and ITS4 (5' TCCTTCCGCTTATTGATATGC G-3'). Additionally, the 5.8S-ITS region and partial 26S gene of the nuclear ribosomal DNA (rDNA) was amplified using the ITS1 primer (5' TCC GTA GGT GAA CCT GCG G 3') and NL4 primer (5' GGT CCG TGT TTC AAG ACG G 3'). The PCR reaction was carried out in $25 \mu$ which was composed of GoTaq ${ }^{\circledR}$ Green Master Mix (Taq DNA polymerase, dNTPs, $\mathrm{MgCl}$ ) (Promega) and $0.5 \mu \mathrm{l}$ of the forward and reverse primers. Amplification conditions for the first primers, ITS1-ITS4, were: initial denaturation $\left(2 \mathrm{~min}\right.$ at $\left.95{ }^{\circ} \mathrm{C}\right)$, final denaturation (1 min at $\left.95{ }^{\circ} \mathrm{C}\right)$, annealing $\left(2 \mathrm{~min}\right.$ at $\left.56^{\circ} \mathrm{C}\right)$, extension $\left(2 \mathrm{~min}\right.$ at $\left.72{ }^{\circ} \mathrm{C}\right)$, and final extension $(10 \mathrm{~min}$ at 72 $\left.{ }^{\circ} \mathrm{C}\right)$. For the first ITS1-NL4, the conditions were: initial denaturation $\left(2 \mathrm{~min}\right.$ at $\left.95{ }^{\circ} \mathrm{C}\right)$, final denaturation
(94 ${ }^{\circ} \mathrm{C}$ for $1 \mathrm{~min}$ ), annealing $\left(40 \mathrm{~s}\right.$ at $52^{\circ} \mathrm{C}$ ), extension $\left(1 \mathrm{~min}\right.$ at $\left.72{ }^{\circ} \mathrm{C}\right)$, final extension $(10 \mathrm{~min}$ at 72 ${ }^{\circ} \mathrm{C}$ ), each for 30 cycles. $4 \mu 1$ of the PCR product were analyzed on $1.5 \%$ TAE $1 \mathrm{X}$ agarose gels and visualized on a FOTO/UV21 Transilluminator. A 100-bp DNA molecular weight marker (Thermo Scientific) was used. The DNA concentration was measured on a Nanodrop, Infinite M200. The amplified DNA was purified and sent for sequencing to Macrogen, Korea.

\subsection{PCR-RFLP technique}

The 5.8S-ITS PCR products $(5 \mu \mathrm{l})$ were digested with the restriction enzymes CfoI, HaeIII (Promega), and Hinfl (New England Biolabs) according to the supplier conditions; these were incubated at $37^{\circ} \mathrm{C}$ for $2.5 \mathrm{hr}$. The fragments were separated on a $3.5 \%$ agarose gel in $1 \mathrm{x}$ TAE for $2 \mathrm{~h}$ at $80 \mathrm{~V}$. Band sizes were estimated by comparison with a 100-bp DNA marker (Thermo Scientific). For the identification of the obtained sequences, the Genbank database was used with the BLAST tool, http://www.ncbi.nlm.nih.gov/BLAST. For in silico characterization, RFLP restriction patterns were predicted by the Restriction Mapper program at: http://www.restrictionmapper.org/.

\subsection{Determination of lipids, proteins, and total phos-} phorus in yeast strains

Independently, flasks containing $50 \mathrm{~mL}$ of vinasse broth (medium) were inoculated with the yeast strains $\left(10^{2} \mathrm{CFU} / \mathrm{mL}\right) ; 77$ strains were tested independently. After inoculation, the flasks were incubated at $23 \pm 2{ }^{\circ} \mathrm{C}$ for 5 days and were maintained on a shaker at $150 \mathrm{rpm}$. After this time, total lipids (TL) were evaluated by the colorimetric Sulfo-PhosphoVanillin (SPV) method; absorbance (A) at $520 \mathrm{~nm}$ was measured. Total Phosphorus (TF) was determined by acid digestion and absorbance (A) at 400 
$\mathrm{nm}$. Total protein (TP) content was determined by Biuret colorimetry; absorbance (A) at $595 \mathrm{~nm}$ was measured. All determinations were undertaken in triplicate. The determination of the lipid profile was undertaken in a gas chromatograph (Varian 2200 GC/MS, Varian CP-3800 GC \& FID Detector) using a VF-23 ms, FS $60 \mathrm{~m}, 0.25 \mathrm{~mm}$ ID $0.25 \mu$ column (VARIAN). The fatty acids were derived as methyl esters, and 35 methyl ester analytical standards (Sigma) were used for the identification.

The obtained data were submitted to statistical analysis using R. Data were analyzed using a one-way analysis of variance (ANOVA) and student's-t tests. The differences observed at $\mathrm{p} \leq 0.05$ were considered significant.

\subsection{Determination of yeast strain potential for use in biofertilizers}

Based on the results of the metabolic analyses, the yeast strains PP1, PP21 and PR28 were selected to be tested as biofertilizers. Specifically, these strains had high nitrogen content (in protein) and high total phosphorus compared to the other strains (PP1: 1.4 $\pm 0.03 \mathrm{mg}$ total phosphorus $/ \mathrm{g}$ dry yeast and 130.5 $\pm 15 \mathrm{mg}$ protein/g dry yeast. PP21: $0.9 \pm 0.00 \mathrm{mg}$ total phosphorus/g dry yeast and $251.3 \pm 7.0 \mathrm{mg}$ dry yeast protein/g. PR 28: $4.83 \pm 0.01 \mathrm{mg}$ of total phosphorus/g dry yeast and $124.9 \pm 6 \mathrm{mg}$ protein/g dry yeast). To test their utility as biofertilizers, each strain $\left(10^{2} \mathrm{CFU} / \mathrm{mL}\right)$ was cultivated in vinasse medium for $72 \mathrm{~h}$, then the culture was centrifuged at $20,000 \mathrm{rpm}$ for $20 \mathrm{~min}$, and the obtained pellet was dried at $70{ }^{\circ} \mathrm{C}$ for $72 \mathrm{~h}$. This pellet was then ground to $\leq 0.1 \mathrm{~cm}$, and the resulting powder constituted the respective biofertilizers (B1; B21; B28). To determine if the biofertilizers positively affected plant growth, they were added to bell pepper seedlings that were grown until the transplanting stage. Each plant was grown in $2 \mathrm{~kg}$ of volcanic ash soil with guano $\left(49.4 \mathrm{~g} /\right.$ tray) and $\mathrm{NH}_{4} \mathrm{NO}_{3}(42.1 \mathrm{~g} /$ tray) additions. B1, B21, B28 (24.6 g/tray), or no fertilizer (control) were added separately to each tray. Bell pepper seeds were added to each tray, which were kept in a greenhouse for 40 days with a $16 \mathrm{~h}$ light $/ 8$ $\mathrm{h}$ dark photoperiod, temperatures between 12 and $30{ }^{\circ} \mathrm{C}$, and a water regimen of distilled water and monthly irrigation with Hoagland solution without nitrogen and phosphorus. Fifteen seedlings per control and treatment were measured in $\mathrm{cm}$ : the total length; long stem, long root and the number of true leaves were counted. The numerical results underwent analysis of variance and the Tukey test $(p<$ $0.05)$ using the $\mathrm{R}$ program. The differences observed at $\mathrm{p} \leq 0.05$ were considered significant.

\section{Results}

\subsection{Physiological characterization of the yeast strains}

From the sequencing of the 77 yeast strains, 10 unique taxa were found. Thus, the strains identified as a given taxon were grouped, yet the physiological characteristics of all 77 strains were determined to verify consistency within taxa. Regarding the assimilation of carbon (Table 1), the strain identified as P. fermentans (B27) had a carbon assimilation profile that was similar to that similar to that described by Kreger-van Rij (1994) for the same yeast specie. Interestingly, none of the strains from the present study were able to assimilate Inositol, and all were able to assimilate Glycerol. The strains grouped into the genus Kazachstania assimilated all of the tested carbon sources with the exception of Inositol, L-Rhamnose, and Salicin. Strains grouped in the Trichosporon genus differed in their carbon assimilation profiles. Specifically, PP2, PR11, and PR12 were identified as 
T. lignicola, yet the strain PR11 did not assimilate DArabinose, D-Ribose, Eritritol, or L-Rhamnose while PR12 and PP2 did assimilate these sugars. Regarding T. dulcitum, the strain PR27 did not assimilate DArabinose, D-Ribose, L-Arabinose, L-Rhamnose or compared to the other strains identified as T. dulcitum which did assimilate these sugars (PR1, PR3, PR4,
PR5, PR8, PR10, PR23, PR24, PR25, PR26). There were differences in the assimilation of some carbon sources by strains identified as T. porosum (PP4, B2, B3, B5, B6, B16, B21). Specifically, the strain PP4 was capable of assimilating D-Arabinose, D-Ribose, L-Rhamnose, Eritritol and Starch while the other strains weakly assimilated these sugars.

Table 1. Example of assimilation of carbon sources for some yeast strains studied in this work

\begin{tabular}{|c|c|c|c|c|c|c|c|c|c|c|}
\hline Species & $\mathbf{C n} *$ & Cs* & Dh* & $\mathrm{Ke}^{*}$ & $\mathbf{P f}^{*}$ & Uf* & Td* & $\mathbf{T l}^{*}$ & Tm* & $\mathbf{T} \mathbf{p}^{*}$ \\
\hline Strain & PR28 & PR16 & PP1 & PP10 & $\overline{B 27}$ & PR9 & PR10 & PR11 & PR29 & B6 \\
\hline $\mathrm{N}^{\circ}$ of strains in this work & 1 & 1 & 9 & 38 & 1 & 5 & 11 & 3 & 1 & 7 \\
\hline Cellobiose & + & + & + & + & - & + & $\mathrm{w}$ & + & + & + \\
\hline Citrate & + & + & + & + & + & + & + & + & + & + \\
\hline D-Arabinose & $\mathrm{w}$ & w & - & + & $\mathrm{w}$ & w & $(-/+)$ & $(-/+)$ & + & $(-/+)$ \\
\hline D-Glucitol & + & + & + & + & - & + & + & + & + & + \\
\hline D-Glucose & + & + & + & + & + & + & + & + & + & + \\
\hline DL-Lactate & w & w & + & + & + & - & + & + & w & - \\
\hline D-Ribose & - & - & $\mathrm{w}$ & + & - & - & $(-/+)$ & $(-/+)$ & - & $(-/+)$ \\
\hline D-Xylose & + & + & $\mathrm{w}$ & + & + & + & + & + & + & + \\
\hline Erythritol & - & - & + & + & - & - & + & $(-/+)$ & + & $(-/+)$ \\
\hline Glycerol & + & + & + & + & + & + & + & + & + & + \\
\hline Inositol & - & - & - & - & - & - & - & - & - & - \\
\hline L-Arabinose & + & w & $\mathrm{w}$ & + & $\mathrm{w}$ & + & $(-/+)$ & + & + & + \\
\hline L-Rhamnose & - & - & $\mathrm{w}$ & - & - & - & $(-/+)$ & $(-/+)$ & - & $(-/+)$ \\
\hline L-Sorbose & + & + & $\mathrm{w}$ & + & - & + & w & + & + & + \\
\hline Melezitose & + & + & + & + & - & + & + & + & + & + \\
\hline Melibiose & + & + & - & + & - & + & $(-/+)$ & + & w & + \\
\hline Raffinose & + & + & w & + & - & + & + & + & + & + \\
\hline Ribitol & + & + & + & + & $\mathrm{w}$ & + & + & + & + & + \\
\hline Salicin & + & + & + & - & $\mathrm{w}$ & + & + & + & + & w \\
\hline Starch & + & w & + & + & $\mathrm{w}$ & $\mathrm{w}$ & + & $\mathrm{w}$ & + & $(-/+)$ \\
\hline Succinate & + & + & + & + & + & + & + & $\mathrm{w}$ & + & w \\
\hline
\end{tabular}

*Abbreviations name yeast: Candida sp. (Cn), strain PR28; Candida saitoana (Cs), strain PR16; Devaryomyces hansenii (Dh), strains PP1, B1, B4, B7, B9, B18, B20, B26, B28; Kazachstania exigua (Ke), strains PP5, PP6, PP7, PP8, PP9, PP10, PP11, PP12, PP13, PP14, PP15, PP16, PP17, PP18, PP19, PP20, PP21, PP22, PP23, PP24, PP25, PP26, PP27, PP28, PP29, PP30, PR5, PR13, PR14, PR15, PR17, PR18, PR19, PR20, PR21, PR22, PR30, B29; Pichia fermentans (Pf), strain B27; Uncultured fungus (Uf), strains PR2, PR7, PR9, B10, B11; Trichosporon ducitum (Td), strains PR1, PR3, PR4, PR5, PR8, PR10, PR23, PR24, PR25, PR26, PR27; Trichoporon lignícola (T1), strains PP2, PR11, PR12; Trichosporon miniiliforme (Tm), strain 
The analysis of fermentation (Table 2) indicated that with the exception of D. hansenni, S. starkeyiihenricii, and strains grouped in the genus Trichosporon ( $T$. ducitum; T. lignicola; T. miniiliforme and T. porosum), the other strains fermented Glucose. Further to this, species of the genus Trichosporon were unable to ferment other carbon sources. The strains PR16 and
PR28 showed a weak positive assimilation of urea. Additionally, the strain PR16 positively assimilated nitrate while PR28 was not able to assimilate nitrate. Additionally, the carbon assimilation profile of the strains PR16 and PR28 were similar; both positively assimilated glucose. However these strains differed in the assimilation of nitrogenous compounds.

Table 2. Example of fermentation of carbon sources and assimilation of nitrogen sources for some yeast strains studied in this work.

\begin{tabular}{|c|c|c|c|c|c|c|c|c|c|c|}
\hline Species & Cn* & $\mathrm{Cs}^{*}$ & Dh* $^{*}$ & $\mathrm{Ke}^{*}$ & Pf* & Uf* & Td* & $\mathbf{T l}^{*}$ & Tm* & Tp* \\
\hline Strain & PR28 & PR16 & PP1 & PP10 & $\mathbf{B 2 7}$ & PR9 & PR10 & PR11 & PR29 & B6 \\
\hline $\mathrm{N}^{\circ}$ of strains in & 1 & 1 & 9 & 38 & 1 & 5 & 11 & 3 & 1 & 7 \\
\hline \multicolumn{11}{|l|}{ this work } \\
\hline \multicolumn{11}{|l|}{ Fermentation } \\
\hline D-Galactose & - & - & - & - & - & - & - & - & - & - \\
\hline D-Glucose & + & + & - & + & + & - & - & - & - & - \\
\hline D-Xylose & - & - & - & - & - & - & - & - & - & - \\
\hline Fructose & + & - & - & + & w & - & - & - & - & - \\
\hline Lactose & - & - & - & - & - & - & - & - & - & - \\
\hline Maltose & - & - & - & - & - & - & - & - & - & - \\
\hline Starch & + & + & + & + & $\mathrm{w}$ & - & - & - & - & - \\
\hline Sucrose & - & - & - & - & - & - & - & - & - & - \\
\hline$\alpha, \alpha$-Trehalose & - & - & - & - & - & - & - & - & - & - \\
\hline \multicolumn{11}{|c|}{ Nitrogen sources assimilation } \\
\hline Nitrate & - & + & - & - & - & - & + & - & + & - \\
\hline Nitrite & $\mathrm{w}$ & - & + & w & $\mathrm{w}$ & $\mathrm{w}$ & + & $\mathrm{w}$ & - & + \\
\hline Urea hydrolysis & $\mathrm{w}$ & $\mathrm{w}$ & + & $\mathrm{w}$ & - & + & $\mathrm{w}$ & + & - & + \\
\hline
\end{tabular}

*Abbreviations name yeast: Candida sp. (Cn), strain PR28; Candida saitoana (Cs), strain PR16; Devaryomyces hansenii (Dh), strains PP1, B1, B4, B7, B9, B18, B20, B26, B28; Kazachstania exigua (Ke), strains PP5, PP6, PP7, PP8, PP9, PP10, PP11, PP12, PP13, PP14, PP15, PP16, PP17, PP18, PP19, PP20, PP21, PP22, PP23, PP24, PP25, PP26, PP27, PP28, PP29, PP30, PR5, PR13, PR14, PR15, PR17, PR18, PR19, PR20, PR21, PR22, PR30, B29; Pichia fermentans (Pf), strain B27; Uncultured fungus (Uf), strains PR2, PR7, PR9, B10, B11; Trichosporon ducitum (Td), strains PR1, PR3, PR4, PR5, PR8, PR10, PR23, PR24, PR25, PR26, PR27; Trichoporon lignicola (T1), strains PP2, PR11, PR12; Trichosporon miniiliforme (Tm), strain PR29; Trichosporon porosum (Tp) strains PP4, B2, B3, B5, B6, B16, B21. Scored for response to tests: negative = -, positive $=+$, weakly positive $=\mathrm{w}$, positive or negative for one or more strains within the group $=(-/+)$. 


\subsection{Molecular identification of yeast strains}

Differences were found in the sizes of the amplified yeast ITS-5.8S rDNA regions; amplified fragments ranged in size from 421 to $678 \mathrm{bp}$. Additionally, ten distinct profiles (i.e. ten taxa) were found from the RFLP analysis with CfoI, HaeIII, and Hinfl (see Table 3).
Of these ten taxa, only four groups, C. saitoana, D.hansenii, K. exigua and P. fermentan, could be identified to species level by comparing the RFLP profiles to those available in the literature, (Esteve Zarzozo et al., 1999). Figure 1 shows the restriction profiles obtained for the yeast group with the greatest number of strains (38).

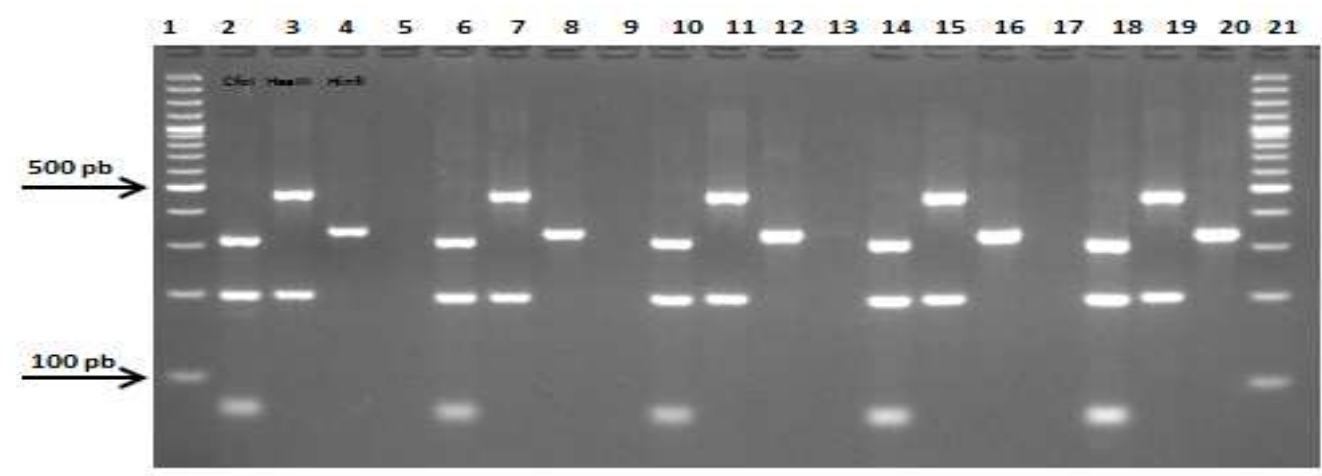

Figure 1. Restriction Enzyme Digestion CfoI, HaeIII, Hinfl for strains PR17 to PR21 (Kazachtania exigua). Lane 1; molecular marker; Lanes 2 (CfoI), 3 (HaeIII), and 4 (Hinfl) strain PR17, Lanes 6 (CfoI), 7 (HaeIII), and 8 (Hinfl) strain PR18, Lanes 10 (CfoI), 11 (HaeIII), and 12 (Hinfl) strain PR19, Lanes 14 (CfoI), 15 (HaeIII), and 16 (Hinfl) strain PR20, Lanes 18 (CfoI), 19 (HaeIII), and 20 (Hinfl) strain PR21, Lane 21; molecular marker

In order to identify the unknown strains (those not identified by PCR-RFLP) and to confirm the identity of the others, the PCR products of 77 strains were sequenced and compared to those available in the GenBank database. From this, the six groups unidentified using PCR-RFLP were identified as $C$. saitoana, T. ducitum, T. miniiliforme, T. lignícola, T. porosum, and $S$. starkeyiihenricii with greater than 99\% max identity. Additionally, the identity of the strains identified using the RFLP method was confirm with the sequencing. The in silico RFLP analysis of the obtained sequences allowed us to identify the fragments that would have been obtained from the endonuclease cutting (Table 3 ) and to compare these with the empirically determined fragments (see Figure 1). The in silico restriction profiles for the following species C. saitoana; D. hansenii; K. exigua; $P$. fermentan; S. starkeyiihenricii and Candida sp. were clearly unique. This was not the case for species of the genus Trichosporon where, for example, the restriction patterns for T. dulcitum, T. lignícola and T. porosum were similar. For T. miniiliforme, although the in silico RFLP profile and profiles generated with the enzymes and cuts with the enzymes $C f o \mathrm{I}$ and Hinfl were similar to those obtained for the other Trichosporon species, there was a clear difference in the restriction pattern obtained with the enzyme HaeIII where no cut occurred. 
Table 3. Identification of yeast strain, size of PCR products and fragments analysis of restriction of the 5.8SITS gene.

\begin{tabular}{|c|c|c|c|c|c|c|c|}
\hline $\begin{array}{l}* \\
\text { Yeast } \\
\text { strain }\end{array}$ & $\begin{array}{l}\text { Query } \\
\text { cover }\end{array}$ & \%Identity & $\begin{array}{l}\text { Identified } \\
\text { taxa/Accession } \\
\text { GenBank Number }\end{array}$ & bp & CfoI & HaeIII & HinfI \\
\hline \multicolumn{4}{|c|}{$\begin{array}{l}\text { Sequencing of the } 5.8 S \text {-ITS and } \\
\text { partial sequence of the } 26 \mathrm{~S} \text { rRNA gene }\end{array}$} & \multicolumn{4}{|c|}{ Analysis RFLP In silico the region ITS-5.8S.(rRNA) } \\
\hline PR28 & $100 \%$ & $97 \%$ & $\begin{array}{l}\text { Candida saitoana } \\
\text { JX188109.1 }\end{array}$ & 616 & $556+50$ & $385+132+99$ & $303+209+96$ \\
\hline PP1 & $100 \%$ & $99 \%$ & $\begin{array}{l}\text { Devariomyces } \\
\text { hansenii } \\
\text { FR686593.2 }\end{array}$ & 640 & $295+284+51$ & $421+139+80$ & $316+316$ \\
\hline B27 & $100 \%$ & $99 \%$ & $\begin{array}{l}\text { Pichia fermentans } \\
\text { GQ458040.1 }\end{array}$ & 447 & $157+92+88+86+69$ & $334+78+35$ & $250+197$ \\
\hline PR9 & $100 \%$ & $99 \%$ & $\begin{array}{l}\text { Uncultured Fungus } \\
\text { KF617918.1 }\end{array}$ & 572 & $304+268$ & n.c & $275+173+124$ \\
\hline PR10 & $99 \%$ & $99 \%$ & $\begin{array}{l}\text { Trichosporon } \\
\text { ducitum } \\
\text { FR716597.1 }\end{array}$ & 533 & $269+264$ & $479+54$ & $229+139+87+61$ \\
\hline PR11 & $99 \%$ & $97 \%$ & $\begin{array}{l}\text { Trichoporon } \\
\text { lignícola } \\
\text { AB180199.1 }\end{array}$ & 533 & $267+266$ & $479+54$ & $229+149+89+61$ \\
\hline PR29 & $100 \%$ & $99 \%$ & $\begin{array}{l}\text { Trichosporon } \\
\text { miniiliforme } \\
\text { AB180198.1 }\end{array}$ & 530 & $266+264$ & n.c & $287+235$ \\
\hline B6 & $99 \%$ & $99 \%$ & $\begin{array}{l}\text { Trichosporon } \\
\text { porosum. } \\
\text { JX243939.1 }\end{array}$ & 528 & $265+263$ & $474+54$ & $234+225+89+61$ \\
\hline PR16 & $100 \%$ & $99 \%$ & $\begin{array}{l}\text { Candida sp. } \\
\text { AJ549823.1 }\end{array}$ & 421 & $216+205$ & n.c & $226+207$ \\
\hline PP10 & $100 \%$ & $97 \%$ & $\begin{array}{l}{ }^{\mathbf{A}} \text { Kazachstania } \\
\text { exigua. } \\
\text { JQ808008.1 }\end{array}$ & 678 & $319+201+76+73$ & $476+202$ & $340+337$ \\
\hline
\end{tabular}

$\mathrm{bp}=$ base pair; $n . c=$ not cut site

*Yeast strains isolated in this work.

A: In Barnett et al., (2000) corresponds to Saccharomyces exiguu

\subsection{Selection of strains with biotechnological potential}

After five days of incubation in vinasse, there was cellular growth of all of the strains (77); growth ranged from $0.18 \mathrm{~g}$ of yeast /L (strain PR27) to $5.58 \mathrm{~g}$ of yeast /L (strain B3). The strain PP12 had the highest amount of total phosphorous ( $1.55 \mathrm{mg} / \mathrm{g}$ of dry yeast), and the greatest amount of total proteins was found in strain
PP4 (409 $\pm 18.5 \mathrm{mg}$ of protein/g of dry yeast). Overall, statistically significant differences $(\mathrm{p}<0.05)$ were found for all three parameters (growth, total phosphorous, and total amount of proteins). The highest values of lipid production were determined for the following strains PP1, PP4, PR4, PR10, PR27 and PR29. As such, these strains were selected as yeast with oleaginous potential. Overall, the statistical analysis indicated that 
there were statistically significant differences in production of lipids among strains $(\mathrm{p}<0.005)$. The yeast selected to be cultivated in vinasse had an average of $214 \pm 36 \mathrm{mg}$ of lipids / $\mathrm{g}$ of dry yeast. The strain with the highest percentage of accumulation of lipids was PP4 (25.8\% lipids with respect to its dry weight of 2.46 $\mathrm{g} / \mathrm{L}$, see Table 4). According to the molecular identification, he strains selected or growth in vinasse be- longed to the genera Devaryomyces (PP1) and Trichosporon (PP4, PR4, PR10, PR27 and PR29). Two strains, PP1 (Devaryomyces hansenii) and PR27 (Trichosporon dulcitum) were selected for lipid profile analysis. From this, it was found that $34 \%$ of the fatty acids of PP1 and $33 \%$ of the fatty acids of PR27 ((Woleic acid /W fatty acids total)*100) were C18:1 oleic acids (cis9).

Table 4, Determination of dry weight, total proteins, total phosphorus and total lipids in strains of yeasts isolated from permanent grassland (PP), ), rotating grassland PR and native forest (B) grown in vinasse medium.

\begin{tabular}{|c|c|c|c|c|c|c|c|c|c|}
\hline Strain & *D.W & $* \mathbf{P}$ & *T.P & $* \mathbf{T} . \mathbf{L}$ & Strain & *D.W & $* \mathbf{P}$ & *T.P & *T.L \\
\hline PR1 & $1926 \pm 28,3$ & $87,5 \pm 11,9$ & $0,3 \pm 0,004$ & $161,0 \pm 14,6$ & PP10 & $811 \pm 225$ & $135,7 \pm 8$ & $0,7 \pm 0,00$ & $166,3 \pm 2,6$ \\
\hline PR2 & $439 \pm 52,3$ & $157,7 \pm 12$ & $0,3 \pm 0,001$ & $256,8 \pm 20,5$ & PP11 & $844 \pm 158$ & $267,0 \pm 4$ & $0,8 \pm 0,00$ & $150,3 \pm 21$ \\
\hline PR3 & $1680 \pm 48,1$ & $204,9 \pm 13,6$ & $0,3 \pm 0,002$ & $199,4 \pm 5,8$ & PP12 & $990 \pm 14$ & $160,7 \pm 21$ & $1,5 \pm 0,00$ & $128,2 \pm 9$ \\
\hline PR4 & $1485 \pm 145$ & $107,8 \pm 17,8$ & $0,3 \pm 0,00$ & $158,2 \pm 7,5$ & PP13 & $689 \pm 72$ & $228,3 \pm 15$ & $1,2 \pm 0,00$ & $198,1 \pm 1,3$ \\
\hline PR5 & $439 \pm 128$ & $121,4 \pm 21,5$ & $0,2 \pm 0,001$ & $114,1 \pm 17,7$ & PP14 & $1529 \pm 197$ & $170,7 \pm 6$ & $0,8 \pm 0,00$ & $141,8 \pm 5,8$ \\
\hline PR6 & $1633 \pm 15,6$ & $122,5 \pm 7$ & $0,3 \pm 0,003$ & $258,9 \pm 16,3$ & PP15 & $1333 \pm 254$ & $168,0 \pm 7$ & $0,6 \pm 0,00$ & $110,8 \pm 6,5$ \\
\hline PR7 & $168 \pm 5,7$ & $121,2 \pm 9,5$ & $0,2 \pm 0,003$ & $261,0 \pm 13,9$ & PP16 & $1377 \pm 24$ & $150,7 \pm 20$ & $0,7 \pm 0,00$ & $149,3 \pm 4,7$ \\
\hline PR8 & $1584 \pm 39,6$ & $91,8 \pm 2,1$ & $0,2 \pm 0,001$ & $128,5 \pm 6,1$ & PP17 & $920 \pm 63$ & $200,0 \pm 8$ & $0,6 \pm 0,00$ & $185,0 \pm 3,5$ \\
\hline PR9 & $346 \pm 25$ & $177,6 \pm 4,7$ & $0,5 \pm 0,002$ & $217,2 \pm 4,7$ & PP18 & $1260 \pm 8$ & $258,3 \pm 6$ & $0,6 \pm 0,00$ & $95,6 \pm 6,7$ \\
\hline PR10 & $1566 \pm 76$ & $135,4 \pm 14,5$ & $0,2 \pm 0,002$ & $240,0 \pm 12$ & PP19 & $959 \pm 83$ & $185,0 \pm 4$ & $0,6 \pm 0,00$ & $174,2 \pm 4,1$ \\
\hline PR11 & $2175 \pm 193$ & $106,4 \pm 27,5$ & $0,1 \pm 0,002$ & $130,7 \pm 13,6$ & PP20 & $1069 \pm 115$ & $198,3 \pm 7$ & $0,5 \pm 0,00$ & $120,2 \pm 14,3$ \\
\hline PR12 & $2425 \pm 123$ & $78,0 \pm 5,8$ & $0,2 \pm 0,002$ & $248,7 \pm 17,8$ & PP21 & $876 \pm 45$ & $251,3 \pm 7$ & $0,9 \pm 0,00$ & $317,2 \pm 12,1$ \\
\hline PR13 & $1966,5 \pm 229$ & $176,1 \pm 7,5$ & $0,2 \pm 0,004$ & $160,6 \pm 11,5$ & PP22 & $1111 \pm 72$ & $212,7 \pm 6$ & $0,6 \pm 0,00$ & $108,4 \pm 6$ \\
\hline PR14 & $841 \pm 7,1$ & $174,7 \pm 8,1$ & $0,1 \pm 0,006$ & $261,0 \pm 7$ & PP23 & $1124 \pm 175$ & $193,7 \pm 23,5$ & $0,3 \pm 0,00$ & $232,3 \pm 12,5$ \\
\hline PR15 & $994 \pm 53,7$ & $81,0 \pm 2$ & $0,0 \pm 0,002$ & $148,7 \pm 1,5$ & PP24 & $1177 \pm 33$ & $259,0 \pm 5$ & $0,5 \pm 0,00$ & $148,7 \pm 13,2$ \\
\hline PR16 & $1311 \pm 43,8$ & $110,1 \pm 17,7$ & $0,2 \pm 0,003$ & $69,3 \pm 17,2$ & PP25 & $1407 \pm 49$ & $176,7 \pm 5$ & $0,7 \pm 0,00$ & $107,3 \pm 5,2$ \\
\hline PR17 & $1844 \pm 263$ & $107,1 \pm 16,3$ & $0,1 \pm 0,003$ & $211,0 \pm 16,3$ & PP26 & $1729 \pm 144$ & $135,7 \pm 15$ & $0,7 \pm 0,00$ & $86,4 \pm 2,6$ \\
\hline PR18 & $2065 \pm 12,7$ & $164,1 \pm 13,9$ & $0,4 \pm 0,003$ & $287,4 \pm 13,9$ & PP27 & $951 \pm 120$ & $234,3 \pm 41$ & $0,5 \pm 0,00$ & $204,3 \pm 3,1$ \\
\hline PR19 & $1945 \pm 43,8$ & $142,1 \pm 6,1$ & $0,1 \pm 0,003$ & $131,7 \pm 6,1$ & PP28 & $991 \pm 122$ & $93,3 \pm 14$ & $1,1 \pm 0,00$ & $220,4 \pm 14,4$ \\
\hline PR20 & $1566 \pm 167$ & $151,6 \pm 4,7$ & $0,1 \pm 0,003$ & $187,5 \pm 4,7$ & PP29 & $859 \pm 105$ & $243,7 \pm 5$ & $0,5 \pm 0,00$ & $168,3 \pm 12,9$ \\
\hline PR21 & $2237 \pm 112$ & $232,2 \pm 14,9$ & $0,2 \pm 0,003$ & $72,7 \pm 14,9$ & PP30 & $982 \pm 120$ & $273,7 \pm 34$ & $0,7 \pm 0,00$ & $140,6 \pm 13,7$ \\
\hline PR22 & $2357 \pm 41$ & $166,2 \pm 10,9$ & $0,3 \pm 0,003$ & $132,9 \pm 10,9$ & B1 & $2123 \pm 174$ & $198,0 \pm 10$ & $1,3 \pm 0,00$ & $206,6 \pm 15,5$ \\
\hline PR23 & $2782 \pm 62$ & $229,9 \pm 8,5$ & $0,1 \pm 0,003$ & $143,1 \pm 8,5$ & B2 & $1465 \pm 35$ & $168,7 \pm 5,1$ & $0,4 \pm 0,00$ & $215,8 \pm 19,7$ \\
\hline PR24 & $1831 \pm 202$ & $258,6 \pm 2$ & $0,4 \pm 0,003$ & $176,2 \pm 15,4$ & B3 & $6002 \pm 286$ & $135,7 \pm 3$ & $0,5 \pm 0,00$ & $82,5 \pm 6,3$ \\
\hline PR25 & $3314 \pm 40$ & $133,7 \pm 17,7$ & $0,1 \pm 0,003$ & $97,3 \pm 14,9$ & B4 & $3261 \pm 369$ & $121,0 \pm 9$ & $0,4 \pm 0,00$ & $154,1 \pm 5,5$ \\
\hline PR26 & $2042 \pm 149$ & $207,5 \pm 16,3$ & $0,1 \pm 0,003$ & $162,6 \pm 10,9$ & B7 & $3824 \pm 458$ & $114,7 \pm 10$ & $0,2 \pm 0,00$ & $98,6 \pm 6$ \\
\hline PR27 & $2067 \pm 10$ & $131,8 \pm 13,9$ & $0,2 \pm 0,003$ & $287,9 \pm 8,5$ & B8 & $6106 \pm 161$ & $178,0 \pm 3$ & $1,0 \pm 0,00$ & $199,7 \pm 3$ \\
\hline
\end{tabular}

continued... 


\begin{tabular}{llllllllll}
\hline PR28 & $2261 \pm 61$ & $124,9 \pm 6$ & $0,0 \pm 0,003$ & $128,8 \pm 15,4$ & B9 & $3262 \pm 337$ & $96,3 \pm 16$ & $1,0 \pm 0,00$ & $253,2 \pm 3$ \\
PR29 & $2858 \pm 59$ & $226,0 \pm 5$ & $0,3 \pm 0,003$ & $212,6 \pm 3,3$ & B10 & $1898 \pm 26$ & $221,7 \pm 12$ & $0,5 \pm 0,00$ & $211,4 \pm 20$ \\
PR30 & $2170 \pm 240$ & $174,1 \pm 0,5$ & $0,2 \pm 0,003$ & $127,0 \pm 11,5$ & B11 & $1620 \pm 447$ & $232,3 \pm 3$ & $0,4 \pm 0,00$ & $221,8 \pm 9$ \\
PP1 & $3924 \pm 124$ & $130,5 \pm 15$ & $1,4 \pm 0,003$ & $227,1 \pm 2$ & B13 & $6300 \pm 161$ & $194,3 \pm 25$ & $0,3 \pm 0,00$ & $181,2 \pm 8$ \\
PP2 & $5576 \pm 57$ & $189,0 \pm 9$ & $0,7 \pm 0,003$ & $128,9 \pm 14,9$ & B16 & $3351 \pm 337$ & $128,3 \pm 4$ & $0,3 \pm 0,00$ & $224,1 \pm 13$ \\
PP3 & $1229 \pm 239$ & $272,0 \pm 18$ & $0,6 \pm 0,003$ & $199,9 \pm 13$ & B18 & $4488 \pm 25$ & $97,3 \pm 13$ & $0,7 \pm 0,00$ & $81,6 \pm 14$ \\
PP4 & $2463 \pm 115$ & $409,0 \pm 18,5$ & $1,3 \pm 0,003$ & $258,2 \pm 8,3$ & B20 & $5686 \pm 345$ & $116,3 \pm 7$ & $0,6 \pm 0,01$ & $182,9 \pm 14$ \\
PP5 & $684 \pm 31$ & $148,3 \pm 12$ & $1,1 \pm 0,003$ & $199,6 \pm 21,5$ & B21 & $5591 \pm 400$ & $136,3 \pm 3$ & $0,2 \pm 0,01$ & $170,2 \pm 16$ \\
PP6 & $798 \pm 168$ & $150,3 \pm 18,4$ & $0,9 \pm 0,003$ & $285,8 \pm 10,7$ & B26 & $5357 \pm 237$ & $141,7 \pm 13$ & $0,6 \pm 0,01$ & $78,1 \pm 12$ \\
PP7 & $759 \pm 12$ & $181,3 \pm 12$ & $0,5 \pm 0,003$ & $296,2 \pm 6,2$ & B27 & $5618 \pm 234$ & $369,7 \pm 2$ & $1,6 \pm 0,00$ & $111,2 \pm 9$ \\
PP8 & $1245 \pm 100$ & $207,4 \pm 14$ & $0,7 \pm 0,00$ & $152,2 \pm 5,5$ & B28 & $3449 \pm 496$ & $189,3 \pm 15$ & $0,6 \pm 0,00$ & $162,4 \pm 8$ \\
PP9 & $1143 \pm 30$ & $190,3 \pm 16$ & $0,9 \pm 0,00$ & $89,9 \pm 2,2$ & & & & & \\
\hline
\end{tabular}

*Values represent the average of three determinations \pm standard deviation. $\mathrm{D} . \mathrm{W}=$ Dry weight $(\mathrm{g} / \mathrm{L}) ; \mathrm{P}=$ Total protein (mg/g dry yeast); T.P= Total Phosphorus (mg/g dry yeast); T.L = Total lipid (mg/g dry yeast).

The yeast strains that were tested for potential use as biofertilizers were PP1, PP21, and PR28, which were identified as the following genera Devaryomyces, $\mathrm{Ka}$ zachstania, and Candida, respectively. The strain PP1 had $1.4 \pm 0.03 \mathrm{mg}$ of total phosphorous/g of dry yeast and $130.46 \pm 0.5 \mathrm{mg}$ of protein/ $\mathrm{g}$ of dry yeast. The strain PP21 had $0.87 \pm 0.06 \mathrm{mg}$ of total phosphorous/ $\mathrm{g}$ dry yeast and $251.3 \pm 3.6 \mathrm{mg}$ of protein/ $\mathrm{g}$ of dry yeast. The strain PR28 was found to have $4.83 \pm 0.01$ $\mathrm{mg}$ of total phosphorous/g of dry yeast and $124.93 \pm$ $12.73 \mathrm{mg}$ of protein/g of dry yeast. The potential use of these strains (PP1, PP21, and PP28) as biofertilizers was determined by measuring the morphometric parameters of bell pepper seedlings suitable for transplantation. The highest mean total length $(9.53 \pm 0.85$ $\mathrm{cm}$ ) was found for bell pepper seedlings grown in the control soil (Figure 2A), and there were significant differences $(p<0.05)$ in the mean total length of these seedlings compared to those grown in guano and with B28 and B1 addition. The highest average stem length $(5.66 \pm 0.99 \mathrm{~cm})$ was found in seedlings treated with $\mathrm{B} 1$ (Figure 2B); there were significant differences ( $\mathrm{p}$ $<0.05$ ) in the average stem length of plants fertilized with guano and with additions of B1, B21, and B28 compared to plants grown in the control soil and those fertilized with $\mathrm{NH}_{4} \mathrm{NO}_{3}$. The highest mean root length $(5.6 \pm 1.59 \mathrm{~cm})$ was found in seedlings fertilized with $\mathrm{NH}_{4} \mathrm{NO}_{3}$ (Figure 2C), and these values differed significantly $(p<0.05)$ from the mean root length of plants fertilized with B1; B21 and B28. Lastly, the highest average number of leaves $3.93 \pm 0.70$ was recorded for bell pepper seedlings treated with B1. 

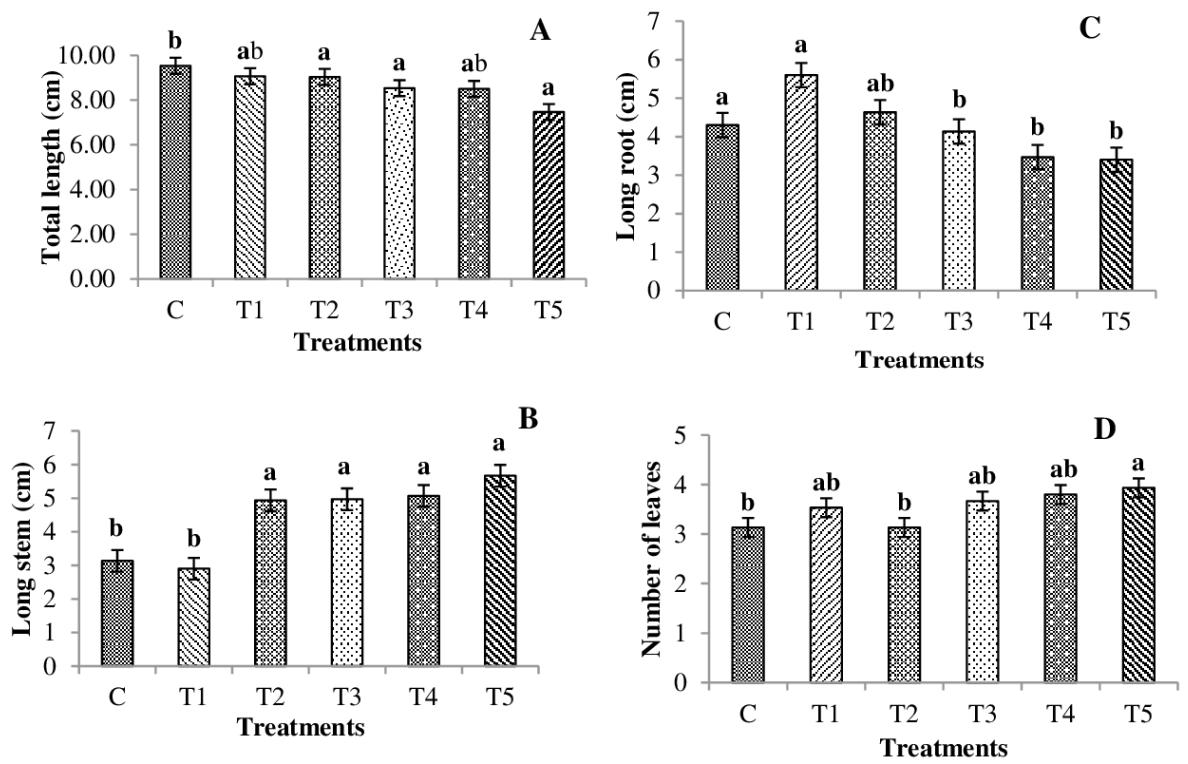

Figure 2. Morphometric parameters determined in bell pepper seedlings. $\mathrm{C}=$ control soil. $\mathrm{T} 1=$ soil with $\mathrm{NH}_{4} \mathrm{NO}_{3}$. $\mathrm{T} 2=$ soil with guano. T3 $=$ soil with B28. T4 = soil with B21. T5 = soil with B1. Different letters in the columns indicate statistically significant differences $(\mathrm{p}<0.05)$. $\mathrm{A}=$ total length in bell pepper seedlings; $\mathrm{B}=$ Long stem: The stem is the central part of aboveground portion of a land plant $C=$ Long root: Main root, $D=$ Number of leaves 


\section{Discussion}

This study demonstrates that physiological analysis and molecular characterization using PCR-RFLPs and sequencing are useful tools for the identification of yeast, and this, in turn, can facilitate the development of biotechnological applications for these microorganisms. The assimilation and fermentation profiles obtained from the physiological characterization of these yeasts were similar with those described in the literature for yeast reference strains. For example, the assimilation of carbon by the strain $P$. fermentans (B27) was similar to that found by Caputo et al. (2012). Furthermore, all of the strains identified as belonging to the genus Kazachstania assimilated the tested carbon sources with the exception of Inositol, L-Rhamnose, and Salicin. These results are similar to those obtained by Liu et al. (2008) for K. exigua.

The carbon assimilation profiles differed among species from the genus Trichosporon. For example, the strain PR27 identified as T. dulcitum did not assimilate D-Arabinose, D-Ribose, L-Arabinosa, Ramhnosa, or Melibiosa while the other strains identified as this species (PR1, PR3, PR4, PR5, PR8, PR10, PR23, PR24, PR25, PR26) did assimilate these sugars. Regardless, the carbon assimilation profiles of some $T$. dulcitum reference strains [CBS 8257, CBS 5785, CBS 5786, CBS 7608, CBS 8258 (http://www.cbs.knaw.nl/)] also differ. Differences were also found among the strains identified as T. porosum (PP4, B2, B3, B5, B6, B16, B21). Specifically, the strain PP4 positively assimilated D-Arabinosa, D-Ribosa, L-Rhamnose, Erythritol and Starch, while the other strains minimally assimilated these sugars. These results are similar to those presented by Middelhoven et al. (2001) for T. porosum (reference strains: CBS 2040, 8396, 8397 and 8522) only that in the mentioned study starch is positively assimilated. Colombo et al. (2011) suggest that these differences between strains depend on the source from which the strains are isolated.
Regarding the fermentation of carbon sources, the results presented here indicate that all of the studied strains (77) ferment glucose with the exception of $D$. hansenni, S. starkeyiihenricii, and strains identified as belonging to the genus Trichosporon (T. ducitum, T. lignicola, T. miiniliforme and T. porosum). With respect to the genus Candida, Yan et al. (2014) have shown that Candida mycoderma obtained from soil from rice cultivation in the Jiangxi province of Chine assimilate nitrogen compounds including $\mathrm{KNO}_{3}$ and Urea. Similarly, Kurztman et al. (2011) indicate that strains from the genus Candida can be nitrate positive or negative and usually do not hydrolyze Urea. The strains PR16 and PR28 were weakly positive for Urea. Additionally, the strain PR16 positively assimilated nitrate, while PR28 did not. With respect to the yeast identification, there are many molecular techniques that employ the use of rDNA gene sequences and/ or ITS regions (Honnavar et al., 2016). Recently, the use of mitochondrial DNA (mtDNA) and ribosomal DNA (RFLP) has been widespread (Kopecká et al., 2016). Here, both RFLP analysis and ribosomal DNA sequencing were used for the identification of yeast. Differences were found in the sizes of the amplified ITS-5.8S regions of the yeast strains (regions ranged in size from 421 to $678 \mathrm{bp}$ ). Taking into account this variability, the 77 strains analyzed here clustered into ten unique groups according to the RFLP profiles. Of these ten groups, four could be identified to species level, and one group could be identified to the genus level (D. hansenii, P. fermentan, $K$. exigua, Candida sp.). Despite this, it has been shown that restriction profiles often do not differ drastically, thus identification to the species level is complicated (Segura et al., 2010). This was the case for the restriction profiles for strains identified as belonging to the genus Trichosporon.

In order to further resolve these profiles, other restriction enzymes should be used to differentiate the strains. Alternatively, sequencing other DNA regions, 
such as intergenic spaces (IGS) located within 26S and 18S, would help resolve species identifications (Romero et al., 2005). At the very least, similarity in the restriction patterns of closely related species is to be expected. Middelhoven et al. (2001) have shown that the ITS-5.8S is highly homologous in species of the genus Trichosporon; thus, this genus is considered phylogenetically monophyletic. Further to this, Segura et al. (2010) reports that the RFLP band patterns for the yeast species Kuyvemyces lactis and Kluveromyces marcianus are very similar, thus correct identification using RFLPs or morphophysiological measurements is complicated. The restriction patterns for the strains identified to the genus Kazachstania were similar to those obtained in other studies (for examples see Pham et al., 2011 and Esteve-Zarzoso et al., 1999).

Following the identification and characterization of the yeast strains, we found that $K$. exigua was the most abundant species in our samples; this species represented $38 \%$ of all of the strains isolated from the Hapludand soils, and it was most prevalent in PP soils. As described by Yurkov et al. (2012), yeasts of the genus Kazaschtania have been reported in many types of soil including those originating from forests and prairies subjected to different types of management. Likewise, Liu et al. (2008) present a new species of the genus Kazaschtania from soil from Taiwan. The yeast species that mainly dominated the B soils were D. hansenii, T. porosum, T. dulcitum and S. starkeyihenricii. In their study conducted in Andian Patagonian forests in Argentina, Mestre et al. (2011) have shown that the species T. dulcitum and $T$. porosum actively participate in the decomposition, degradation, and mineralization of plant material. The results obtained here also support the finding that T. dulcitum, T. porosum, and Cryptococcus Podzolicus are involved in the decomposition of complex polysaccharides and some aromatic compounds (Yurkov et al., 2012).
Additionally, it has been described that yeast belonging to the following genera Candida, Cryptococcus, Rhodotorula, Sporobolomyces, Trichosporon, Williopsis and Yarrowia are capable of directly increasing plant growth (Botha, 2011). Strains identified as belonging to the genus Kazachstania were most abundant in the PP soil ( $87 \%$ of the strains isolated from the PP samples). This is consistent with results found by Yurkov et al. (2012) that show that with increased intensity of soil management there is a greater proportion of Ascomycete yeast. Overall, two possible biotechnological applications, the production of lipids and use as biofertilizers, have been identified for the yeast isolated in the present study (see Table 4). Specifically, lipid-producing yeast could present an alternative for the production of biodiesel. In the present study, the strains PP1, PP4, PR4, PR10, PR27 Y PR29 had the highest values of lipid production.

According to the molecular identification, these strains are classified as $D$. hansenni (PP1) and belonging to the genus Trichosporon (PP4, PR4, PR10, PR27 and PR29). Interestingly, Breuer and Harms (2006) have indicated that $D$. hansenni is metabolically versatile yeast that is osmotolerant, non-pathogenic, and has the capacity to accumulate lipids. Thus, these authors indicate that this microorganism is attractive from a biotechnological viewpoint. Upon cultivating a new strain of Devaryomyces etchellsii in limited nitrogen conditions, Arous et al. (2015) found an increase in lipids from the vegetative stage $(11.9 \%)$ to ascoporogenesis $(22.4 \%)$. Here it was found that the strain PP1 identified as D. hansenni was able to accumulate $22.2 \%$ of lipids when grown in vinasse. Some studies have also noted the ability to accumulate lipids by species of the genus Trichosporon. For example, Gao et al. (2014) found a high accumulation of lipids $12.3 \mathrm{~g}$ of lipids/ L of hydrolyzed lignocellulose with respect to dry cellular biomass (38.4 g) in Trichosporon cutaneum ACCC 20271 when grown in a corncob media 
(lignocellulose residue). These values are quite high considering that the cultivation media was a lignocellulose residue, which are known to contain inhibitors (see Kumar et al., 2017).

In the present study, after six days of incubation in vinasse, $11.3 \mathrm{~g}$ of yeast /L of vinasse were obtained, and the yeast was composed of $30 \%$ lipids. Another study evaluating the yeast Trichosporon oleaginosus grown in sewage treatment sludge (thermally and chemically pretreated) found a lipid content of 39\% (Zhang et al., 2014). Here the highest lipid content obtained for strains of the genus Trichosporon was found for the strains PP4 and PR27 (25.8 and 21.6\%, respectively). Finally, two strains were selected for lipid profile analysis, these included PP1 identified as D. hansenni and PR27 identified as T. dulcitum. From this, it was found that strain PP1 had 34\% ((Woleic acid $/ \mathrm{W}_{\text {total fatty ac- }}$ ids)*100) oleic acid C18:1 (cis9) while strain PR27 had $33 \%$ oleic acid. The composition of these oils indicates that they are suitable as raw material for the production of biodiesel (Soccol et al., 2017). The strains PP1 (D. hansenii), PP21 (K. exigua), and PR28 (Candida sp.) were tested for potential use as biofertilizers, and interestingly it has reported that yeast of these genera are promoters of plant growth due to their production of different biomolecules. For example, Fu et al. (2016) have isolated 15 species of growth promoting yeast from the phylosphere and rhizosphere of the plant Drosera spatulata Lab., and these 15 species include Kazachstania jiainicus (FJ196732) and Candida akabanensis (EU100744). Yet other studies demonstrate the capacity of isolated yeast, including Kazachstania siamensis LM002 and Candida sirachaensis LM068, to biosynthesize, Indole-3-Acetic Acid (IAA) (43.3 $\mathrm{mg} / \mathrm{L}$ IAA and $31.9 \mathrm{mg} / \mathrm{L}$ IAA, respectively). Furthermore, Narsian et al. (2010) isolated 25 yeast strains and six of these belonging to the genera Saccharomyces; Hansenula; Klockera; Rhodotorula and Debaryomyces had the highest solubilization indices (ranging from
1.33 to 1.50 ) when the yeasts were examined in vitro with tricalcium phosphate and rock phosphate.

Other studies evaluating the effect of the solubilization of phosphates on the growth of plants have found that inoculation with phosphate solubilizing microorganisms (bacterium) produces increase biomass compared to that found for plants that were not inoculated (Sharon et al., 2016). Here it was found that adding yeast to bell pepper seedlings mainly promoted an increase in the number of leaves and an increase in root size produced by the plants (Figure 2). Interestingly, others have found similar effects on root size and number of lateral roots for bean seedlings (Gupta et al., 2016).

\section{Conclusion}

This study has provided initial information on yeast associated with soil with different agricultural management in the region of Los Ríos, Chile. The PCRRFLP methodology was found to be an appropriate technique (fast and reliable) for the identification of yeast. Despite this, not all RFLP profiles were resolvable, thus not all identifications could be performed. Regardless, when complemented with the sequencing of yeast DNA, the identification of the strains was achieved, and sequencing also confirmed the identifications using the PCR-RFLP methodology. In addition, the physiological characteristics of native yeasts of southern Chile are presented here. Thus, a preliminary evaluation of their biotechnological potential as biofertilizers or for lipid production is given; however, future more detailed studies are warranted to better determine the application of these yeasts to industry.

\section{Acknowledgements}

The authors thank the FONDECYT 1141066 project and the National Doctorate Scholarship Number: 21140135, CONICYT. 


\section{References}

Arous, F., Triantaphyllidou, I., Mechichi, T., Azabou, S., Nasri, M., Aggelis, G. 2015. Lipid accumulation in the new oleaginous yeast Debaryomyces etchellsii correlates with ascosporogenesis. Biomass and Bioenergy. 80, 307-315.

Barnett, A.R., Payne, W., Yarrow, D. 2000. Yeast: Characteristics and Identification, Cambridge. Cambridge University Press: 49-77

Breuer, U., Harms, H. 2006. Debaryomyces hansenii - an extremophilic yeast with biotechnological potential. Yeast. 23, 415-437.

Caputo, L., Quintieri, L., Baruzzi, F., Borcakli, M., Morea, M. 2012. Molecular and phenotypic characterization of Pichia fermentans strains found among Boza yeasts. Food Research International. $48,755-762$

Chang, Y., Chang, K.S., Hsu, C.L., Chuang, L.T., Chen, C.Y., Huang, F.Y., Jang, H.D. 2013. A comparative study on batch and fed-batch cultures of oleaginous yeast Cryptococcus sp. in glucosebased media and corncob hydrolysate for microbial oil production. Fuel. 105, 711-717.

Colombo, A., Padovan, A., Chaves, G. 2011. Current Knowledge of Trichosporon spp. and Trichosporonosis. Clinical Microbiology Reviews. 24, 682-700.

El-Tarabily, K., Sivasithamparam, K. 2006. Potential of yeasts as biocontrol agents of soil-borne fungal plant pathogens and as plant growth promoters. Mycoscience. 47, 25-35.

Esteve-Zarzoso, B., Belloch, C., Uruburu, F., Querol, A. 1999. Identification of yeasts by RFLP analysis of the 5.8S rRNA gene and the two ribosomal internal transcribed spacers. Int. J. Syst. Bacteriol. 49, 329-337.
Fernández-González, M., Espinosa, J.C., Úbeda, J.F., Briones, A.I. 2001. Yeasts present during wine fermentation: comparative analysis of conventional plating and PCR TTGE. Syst. Appl. Microbiol. 24, 634-638.

Fu, S.F., Sun, F.P., Lu, H.Y., Wei, J.Y., Xiao, H.S., Fang, W.T., Cheng, B.Y., Chou, J.Y. 2016. Plant growth-promoting traits of yeasts isolated from the phyllosphere and rhizosphere of Drosera spatulata Lab. Fungal Biology. 120, 433-448.

Gao, Q., Cui, Z., Zhang, J., Bao, J. 2014. Lipid fermentation of corncob residues hydrolysate by oleaginous Yeast Trichosporon cutaneum. Bioresource Technology. 152, 552-556.

Gupta, H., Saini, R.V., Pagadala, V., Kumar, N., Sharma, D.K., Saini, A.K. 2016. Analysis of plant growth promoting potential of endophytes isolated from Echinacea purpurea and Lonicera japonica. Journal of Soil Science and Plant Nutrition. $16,558-577$.

Honnavar, P., Prasad, G.S., Ghosh, A., Dogra, S., Handa, S., Rudramurthy, S.M. 2016. Malassezia arunalokei sp. nov., a Novel Yeast Species Isolated from Seborrheic Dermatitis Patients and Healthy Individuals from India. Journal of Clinical Microbiology. 54, 1826-1834.

Ignatova, L., Yelena, V., Brazhnikova, V., Berzhanova, R., Mukasheva, T. 2015. Plant GrowthPromoting and Antifungal Activity of Yeasts from Dark Chestnut Soil. Microbiol. Res. 175, 78-83.

Kopecká, J., Němec, M., Matoulková, D. 2016. Comparison of DNA-based techniques for differentiation of production strains of ale and lager brewing yeast. J. Appl. Microbiol. 120, 1561-1573.

Kumar, D., Bhaskar, S., Korstad, J. 2017. Utilization of Lignocellulosic Biomass by Oleaginous Yeast and Bacteria for Production of Biodiesel and Renewable Diesel. Renew. Sus. Energ. Rev. 73, 654-71. 
Kupper, K.C., Bettiol, W., de Goes, A., de Souzac, P.S., Bellotte, J.A.M. 2006. Biofertilizer for control of Guignardia citricarpa, the causal agent of citrus black spot. Crop Protection. 25, 569-573.

Kurztman, C.P., Fell, J.W., Boekhout, T. 2011. The yeasts a taxonomic study. The Fifth Edition. Elsevier.

Ledesma-Amaro, R., Nicaud, J.M. 2016. Yarrowia lipolytica as a biotechnological chassis to produce usual and unusual fatty acids. Progress in Lipid Research. 61, 40-50.

Liu, Y.R., Liu, C.H., Young, S.S., Lee, C.F. 2008. New Records of Kazachstania Species in Taiwan. Taiwania. 53, 293-300.

Mestre, M., Rosa, C., Safar, S., Libkind, D., Fontenla, S. 2011.Yeast communities associated with the bulk-soil, rhizosphere and ectomycorrhizosphere of a Nothofagus pumilio forest in northwestern Patagonia, Argentina. Microbiology Ecology. 78, 531-541.

Middelhoven, W.J., Scorzetti, G., Fell, J.W. 2001. Trichosporon porosum comb. nov., an anamorphic basidiomycetous yeast inhabiting soil, related theloubieri/laibachii group of species that assimilate hemicelluloses and phenolic compounds. FEMS Yeast Research. 1, 15-22

Narsian, V., Samaha, S.M.A.A., Patel, H.H. 2010. Rock phosphate dissolution by specific yeast. Indian J. Microbiol. 1, 50-57.

Pham, T., Wimalasena, T., Box, W.G., Koivuranta, K., Storgårds, E., Smart, K.A., Gibson, B.R. 2011. Evaluation of ITS PCR and RFLP for differentiation and identification of brewing yeast and brewery 'wild' yeast contaminants. J. Inst. Brew. 117, $556-568$.

Polburee, P., Yongmanitchai, W., Lertwattanasakul, N., Ohashi, T., Fujiyama, K., Savitree, L., 2015. Characterization of oleaginous y easts accumulating high levels of lipid when cultivated in glycerol and their potential for lipid production from biodiesel-derived crude glycerol. Fungal Biology. 119, 1194-1204.

Rakicka, M., Lazar, Z., Dulermo, T., Fickers, P., Nicaud, J.M. 2015. Lipid production by the oleaginous yeast Yarrowia lipolytica using industrial by-products under different culture conditions. Biotechnology for Biofuels. 8, 104.

Romero, P., Patiño, B., Quirós, M., González-Jaén, M.T., Valderrama, M.J., de Silóniz, M.I., Peinado, J.M. 2005. Differential detection of Debaryomyces hansenii isolated from intermediate-moisture foods by PCR-RFLP of the IGS region of rDNA. FEMS Yeast Research. 5, 455-461.

Segura, L., Kirchmayr, M., Flores, E., Gschaedler, A. 2010. PCR-RFLP of the ITS-5.8S regions as an identification tool for yeasts: advantages and disadvantages. e-Gnosis. 8, 1-12.

Sharon, J.A., Hathwaik, L.T., Glenn, G.M., Imam, S.H., Lee, C.C. 2016. Isolation of efficient phosphate solubilizing bacteria capable of enhancing tomato plant growth. Journal of Soil Science and Plant Nutrition. 16, 525-536.

Slavikova, E., Vadkertiova, R. 2000. The occurrence of yeasts in the forest soils. J. Basic Microbiol. 40, 207-212.

Slavikova, E., Vadkertiova, R. 2003. The diversity of yeasts in the agricultural soil. J. Basic Microbiol. $43,430-436$.

Soccol, C.R. et al. 2017. Pilot Scale Biodiesel Production from Microbial Oil of Rhodosporidium Toruloides DEBB 5533 Using Sugarcane Juice: Performance in diesel engine and preliminary economic study. Bioresource Technology. 223, 259-268.

Wuczkowski, M., Prillinger, H. 2004. Molecular identification of yeasts from soils of the alluvial forest national park along the river Danube downstream of Vienna, Austria ("National park 
donauauen"). Microbiological Research. 159, 263-275.

Yan, M., Yu, L., Zhang, L., Guo, Y., Dai, K., Chen, K. 2014. Phosphatase activity and culture conditionsof the yeast Candida mycoderma sp. and analysis of organic phosphorus hydrolysis ability. Journal of Environmental Sciences. 26: 2315-2321.
Yurkov, A., Kemler, M., Begerow, D. 2012. Assessment of yeast diversity in soils under different management regimes. Fungal Ecology. 5, 24-35.

Zhang, X., Yan, S., Tyagi, R., Surampalli, R.Y., Valéro, J. 2014. Lipid production from Trichosporon oleaginosus cultivated with pre-treated secondary wastewater sludge. Fuel. 134, 274-282. 